\title{
Poluição do Ar e Doenças Respiratórias: Uma Revisão
}

\section{Air Pollution and Respiratory Diseases: A Review}

\author{
Milena P. Duchiade'
}

DUCHLADE, M. P. Air Pollution and Respiratory Diseases: A Review. Cad. Saúde Públ., Rio de Janeiro, 8 (3): 311-330, jul/set, 1992.

Although it has been known for many years that smoking is the major air pollutant capable of harming the respiratory system, there is no similar agreement about the effects of other atmospheric pollutants on health. This paper reviews recent publications about the action of major air pollutants, including suspended particulate matter, sulfur dioxide, nitrogen dioxide and ozone, among others. Most studies are based on adult mortality data, although there are also papers that analyse the effects of air pollution on child and adult morbidity. Initial studies came from London and New York but, today many Canadian, American and European researchers are also now working in this area. A few Brazilian studies were also reviewed in order to provide a general picture of the knowledge available so far.

Keywords: Air Pollution; Respiratory Diseases, Environmental Health; Environmental Toxicology

\section{INTRODUÇÃO}

Entende-se como poluente atmosférico qualquer forma de matéria ou energia com intensidade e em quantidade, concentração, tempo ou características em desacordo com os niveis estabelecidos e que tome ou possa tomar o ar:

- Impróprio, nocivo ou ofensivo à saúde;

- Inconveniente ao bem estar público;

- Danoso aos materiais, à fauna e flora;

- Prejudicial à segurança, ao uso e gozo da propriedade e às atividades normais da comunidade (Conama, 1990).

O principal poluente do ar que lesa as vias respiratórias, nas sociedades urbanas contemporâneas, é o fumo. Embora fosse suspeitado desde longa data como responsável por inúmeros danos à saúde, foi particularmente a partir da década de $\mathbf{5 0}$ que começou a se estudar, de modo exaustivo, os efeitos do tabagismo. Os trabalhos de Doll \& Hill (1954), hoje clássicos,

\footnotetext{
'Departamento de Epidemiologia e Métodos Quantitativos em Saude da Escola Nacional de Saúde Pública. Rua Leopoldo Bulhōes, 1480, 8 andar, Rio de Janeiro, RJ, 21041-210, Brasil.
}

comprovaram, a importância do cigarro no aumento dos casos de câncer de pulmão, fato este que já se tomou de domínio público, tão forte foi a associação encontrada. Sabemos hoje que o hábito de fumar contribui de modo significativo não apenas para as neoplasias das vias respiratórias (boca, laringe e pulmão), mas também para diversas outras neoplasias, tais como de bexiga, rim, pâncreas, esôfago, estômago, etc. (Fielding, 1986). Por outro lado, as doenças pulmonares obstrutivas crônicas (asma, bronquite e enfisema), bem como doenças cardiovasculares (hipertensão arterial, angina pectoris e infarto do miocárdio, por exemplo), têm no fumo importante agente etiológico.

Entretanto, percebeu-se, bem mais tardiamente, que o fumo, além de prejudicar os fumantes em si, também afetava os não-fumantes, através do que se convencionou denominar "fumo passivo". Pesquisas em adultos demonstraram que não-fumantes expostos a ambientes de trabalho enfumaçados absorviam em 8 (oito) horas diárias o equivalente ao consumo de um fumante leve, cerca de 5 (cinco) cigarros. Também as crianças são vítimas do cigarro (Greenberg et al., 1984; Bonham \& Wilson, 1981; Ferguson et al., 1981; Fielding, 1986; OMS, 1979). 
O consenso atingido a respeito do papel nocivo do cigarro sobre a saúde das crianças levou os organismos internacionais a incluirem a recomendação de proteger as crianças da exposição ao fumo em todas as resoluçōes oficiais sobre controle das IRAs (OMS/Unicef, 1985). Também o Ministério da Saúde do Brasil recomenda, em seu manual de "Assistência e Controle das IRAs", evitar que a criança fique em ambientes poluídos por fumaça causada por fogo ou cigarros (Ministério da Saúde, 1984). Trata-se, portanto, da poluição doméstica, que ocorre no próprio lar da criança e cuja responsabilidade principal recai sobre os adultos que lá convivem.

Além do cigarro, outros agentes podem poluir o ar que se respira em casa, originando a poluição domiciliar - indoor pollution. São eles a fumaça produzida pela combustão de biomassa (lenha, folhas, esterco, etc) particularmente importante nas áreas rurais, os produtos gerados pela combustão do gás de cozinha (para a preparação de alimentos, para o aquecimento de água e da própria casa), pesticidas e solventes empregados para limpeza, asbestos utilizados para isolamento contra incêndios, etc. (Last, 1986; Pandey, 1989). Estes poluentes tornam-se tão mais importantes quanto mais diferente é o ambiente doméstico com relação ao ar externo. Nos paises temperados, onde durante o inverno as casas permanecem quase sempre fechadas para evitar o frio, a poluição doméstica vem merecendo atenção crescente, motivando inúmeras pesquisas.

Já em nosso meio, onde as casas permanecem com as janelas abertas praticamente o dia inteiro (exceto quando chove), durante todos os meses do ano, permitindo uma ventilação relativamente melhor, $o$ ar dentro das residências tende a igualar-se ao ar livre (Romieu, comunicação pessoal).

Diferentemente do que ocorre com o fumo, não se formou ainda o mesmo consenso a respeito da importância da poluição atmosférica na gênese das IRAs. Apesar de numerosos estudos laboratoriais e populacionais já terem demonstrado o papel lesivo da poluição do ar para as vias respiratónias, esta preocupação ainda não se traduz em propostas concretas nas recomendações oficiais.

Entretanto, nos últimos 60 anos, três episó- dios dramáticos - no Vale do Mosa, Bélgica, em 1930; em Donora, Pensilvânia, em 1948; e em Londres, em 1952 - alertaram as autoridades para as graves consequiências causadas por períodos agudos de poluição (OPS/OMS, 1976). Desde então, multiplicaram-se os estudos sobre os efeitos da poluição do ar na saúde humana.

\section{ESTUDOS INTERNACIONAIS}

Num simpósio internacional realizado em Porto Rico, em 1977, especialistas de todo o mundo sistematizaram os conhecimentos disponíveis até aquela data sobre os efeitos das partículas em suspensão na saúde humana (Holland et al., 1970). Definem-se como "partículas em suspensão" todas as partículas sólidas ou líquidas contidas no ar, de dimensão suficientemente reduzida para não se depositar muito rapidamente por gravidade na superfície terrestre. Podem ser extraídas do ar pela passagem através de um filtro apropriado (OMS, 1987, p. 82). Os particulados incluem poeiras, fumos, nevoeiro, aspersāo e cerraçāo (Broile, 1983). Nesta revisão, os autores discutem, inicialmente, a própria definição de partículas em suspensão, lembrando que as partículas maiores - acima de 10 micra - são conhecidas como "poeiras ou grãos sedimentáveis" e costumam ser depositadas próximas à sua fonte de emissão, normalmente indústrias; as partículas menores, também denominadas de "fumo" ou "fumaça" (smoke or fume), possuem velocidade desprezivel e podem, portanto, ser inaladas, sendo assim mais relevantes na etiologia de problemas respiratórios. Dentre estas últimas, as menores, com diâmetro variando entre 0,1 micron e 2,3 micra, são as mais importantes, pois podem penetrar profundamente nos pulmões, com o risco de lá se acumularem. A composição das partículas em suspensão é complexa e altamente variável, dependendo da natureza das fontes de emissão. Podem ser compostas por carbono, hidrocarbonetos derivados do carvão a partir de combustão incompleta, por cinzas inorgânicas produzidas pela combustão de combustiveis sólidos, por sulfato de amônio (pela conversão de dióxido de enxofre) e, mais localizadamente, por emissōes industriais de óxido de ferro 
(procedentes de siderúrgicas) ou poeira de cimento (pedreiras) (Holland et al., 1979).

Ainda segundo os autores, alguns fatores básicos afetam a concentração destas partículas no ar: a taxa de emissão do poluente, as condições meteorológicas e a topografia local. As condições meteorológicas são particularmente importantes, na medida em que os ventos turbulentos ajudam a dispersar os poluentes. Estes também são depositados pelas chuvas, que "lavam" o ar. A combinação da estabilidade atmosférica com ausência de chuvas torna-se, assim, profundamente desfavorável à dispersão dos poluentes.

Fenômenos ligados à pressão atmosférica também interferem na poluição do ar. Normalmente, devido ao decréscimo de pressão com a altura, as parcelas de ar situadas a altitudes maiores encontram menor pressão, se expandem, e portanto, se resfriam. Esse processo de resfriamento com a ascensão, ou de aquecimento com a descida, é chamado de "curva adiabática seca", equivalente a aproximadamente $1^{\circ} \mathrm{C}$ para cada 100 metros, e não deve ser confundido com a variação da temperatura com a altitude num dado momento, chamada de curva ambiente real (de 4 a $8^{\circ} \mathrm{C}$ por $\mathrm{km}$ ), que ocorre na troposfera, parte da atmosfera situada entre 0 e $8 \mathrm{~km}$ de altitude. A troposfera, camada inferior da atmosfera terrestre, está compreendida entre o solo e uma altitude que varia de $9 \mathrm{~km}$, nos pólos, a $17 \mathrm{~km}$, no Equador; nesta camada, a temperatura decresce regularmente com a altitude. Em seguida, vem a tropopausa, que constitui o limite com a camada seguinte, a estratosfera; esta vai até cerca de 50 a $55 \mathrm{~km}$ de altitude e nela a temperatura, em geral, cresce à medida em que se afasta da terra. A estratopausa compõe a camada seguinte, que limita a mesosfera, onde novamente a temperatura passa a cair com a altitude. O limite da mesosfera é a mesopausa, situada entre 80 a 85 $\mathrm{km}$ de altitude (OMS, 1987). Os fenômenos que influenciam a dispersão dos poluentes do ar atuam na baixa troposfera, entre 0 e $2 \mathrm{~km}$; são estes que podem causar danos imediatos à saúde humana (Sales, 1978). O acúmulo de dióxido de carbono, proveniente da queima de combustiveis fósseis, também causa alteraçōes em toda a atmosfera, através do "efeito estufa", o que pode, a médio prazo, refletir-se nas condições de vida da espécie humana sobre a Terra. Todavia, não vamos discutir este último problema em nosso trabalho; nos limitaremos apenas aos aspectos relacionados à poluição do ar nas camadas mais baixas da atmosfera, onde estão situadas as cidades.

Ainda quanto às condiçōes meteorológicas, uma questão importante é a da chamada "inversão térmica". Nos meses de inverno, sob condições de calmaria (ausência de ventos) e céu claro, ocorre perda de calor por radiação durante a noite, o que faz com que o ar em contato com o solo se resfrie e se torne mais denso do que a camada de ar imediatamente acima. Com o aumento da camada fria, os gases e fumaças poluídos ficam então "presos" na interface de uma camada quente e outra fria. A situação normal (queda da temperatura do ar com o aumento de altitude) é assim revertida, o ar frio ficando abaixo de uma "tampa" de ar quente e poluído, o que gera o fenômeno da dita inversão térmica, que surge acompanhada de camadas de denso nevoeiro a baixa altitude (Holland et al., 1979). Também a umidade relativa do ar e a luz solar interferem nas reações químicas que envolvem os poluentes. Assim, o dióxido de enxofre e os óxidos de nitrogênio, emitidos sob a forma de gases, podem ser convertidos, respectivamente, em sulfatos ou nitratos, aumentando a carga total de partículas em suspensão.

Os óxidos de nitrogênio, designados genericamente por $\mathrm{NO}_{x}$, constituem uma série de sete compostos, dos quais três importantes na atmosfera. $\mathrm{O}$ óxido nitroso $\left(\mathrm{N}_{2} \mathrm{O}\right.$ - protóxido de nitrogênio ou gás hilariante), gás incolor, o mais abundante dos compostos atmosféricos, nāo é importante enquanto poluente, apesar de jogar papel destacado no ciclo do nitrogênio. $O$ monóxido de nitrogênio, ou óxido nítrico (NO), é um gás tóxico incolor que reage espontaneamente com o oxigênio, e muito fortemente com o ozônio, formando o dióxido de nitrogénio. Forma-se nos processos de combustão, por exemplo nas caldeiras e motores de combustão interna, aumentando sua produção com a elevação de temperatura e participando ativamente das reaçōes atmosféricas que sāo a causa do smog fotoquímico. $O$ dióxido de nitrogénio $\left(\mathrm{NO}_{2}\right)$ é um gás avermelhado forte- 
mente tóxico (vapores nitrosos). Nas temperaturas correntes, o vapor é uma mistura de $\mathrm{NO}_{2}$ e do dimero $\mathrm{N}_{2} \mathrm{O}_{4}$ - com o aumento da temperatura, o $\mathrm{N}_{2} \mathrm{O}_{4}$ se dissocia, aumentando, assim, o teor de $\mathrm{NO}_{2}$ Acima de $140 \mathrm{C}$, o $\mathrm{NO}_{2}$ se dissocia em NO e oxigênio. O termo dióxido de nitrogênio e a fórmula $\mathrm{NO}_{2}$ designam a mistura $\mathrm{NO}_{2}$ e $\mathrm{N}_{2} \mathrm{O}_{4}$ em equilibrio. O termo "óxidos de nitrogênio" e o símbolo $\mathrm{NO}_{\mathrm{x}}$ sāo utilizados na literatura sobre poluição do ar para designar a mistura de $\mathrm{NO}$ e $\mathrm{NO}_{2}$ no ar. (OMS, 1987)

Por sua vez, a topografia local afeta a concentração de poluentes. Assim, os vales sujeitos a frequientes calmarias e inversões apresentam as piores condições para a dispersão de gases tóxicos (Holland et al., 1978).

Anderson (1967), citado por Holland et al. (1978), sistematizou os principais problemas relacionados à epidemiologia da poluição do ar, entre os quais destacamos os seguintes:

1) As condiçōes meteorológicas afetam a interpretaçāo dos dados de poluição e podem aumentar a duração da exposição aos poluentes ac impedir sua dissipaçāo;

2) Não existe consenso acerca de quais os poluentes que prejudicam de fato a saide $e$ precisam, portanto, ser medidos e acompanhados;

3) As áreas mais poluidas tendem a ser as áreas onde vive a população mais pobre (op. cit, p. 537).

Um último ponto, talvez o mais importante, é que não se conhece ainda a natureza exata dos agentes poluidores lesivos à saúde, ou os mecanismos pelos quais eles agem. Os autores distinguem, todavia, 3 (três) tipos principais de reação aos poluentes:

a) Os efeitos agudos em pessoas sadias, exemplificados pelas reações a episódios agudos de smog ou a aumentos súbitos dos niveis de poluição, particularmente nos ambientes industriais ou sob condições experimentais;

b) A exacerbação de doenças préexistentes em indivíduos vulneráveis, com cardiopatias ou enfermidades respiratórias prévias, que, ao serem expostos à poluição, podem piorar seus sintomas ou até mesmo vir a falecer;

c) Fenômenos de hipersensibilidade de origem imunológica ou de hiperreatividade brônqui- ca não-específica, que, apesar de não suficientemente esclarecidos, podem ser particularmente relevantes na medida em que causem danos reversiveis (parcial ou totalmente) ou provoquem problemas crônicos (Holland et al., 1979).

Apesar destas ressalvas, não parece haver dúvidas acerca dos efeitos nocivos de episódjos agudos de poluição de ar intensa sobre as vias respiratórias, levando ao agravamento de sintomas em individuos vulneráveis (portadores de problemas respiratórios crônicos) e até mesmo à morte.

As principais evidências a respeito dos efeitos a curto prazo da poluição do ar vêm, sobretudo, de estudos realizados em Londres e, secundariamente, de pesquisas feitas na cidade de Nova York. Na revisão já citada, Holland et al. (1979) recuperaram informações dando conta do aumento no número de mortes esperadas, associado à piora do smog londrino, desde 1873 até 1975 , ou seja, por mais de 100 anos. Mesmo após 1952, ano que foi palco do episódio mais grave e a partir do qual o governo intensificou o combate à poluição, tal associação continuou a ser constatada em numerosos invernos.

Assim, Martin \& Bradley (1960) estudaram o inverno de 1958-59, quando diversos dias com poluição elevada coincidiram com um aumento no número de mortes por todas as causas. Foram encontradas uma associação positiva e significativa entre a concentração de partículas em suspensão e o número diário de mortes e uma correlação um pouco menor, porém ainda significativa, entre a quantidade de dióxido de enxofre e a mortalidade.

Mazumdar et al. (1982) prosseguiram estudando o smog londrino durante 14 invernos, de 1958 a 1972. Utilizaram três tipos de análise estatística: regressão múltipla ano-a-ano; estratificação dos dados sob forma de quartis vizinhos, segundo dois tipos de poluentes - fumaças e $\mathrm{SO}_{2}$, de modo a reduzir a colinearidade; estudo de um subconjunto de dias mais intensamente poluidos, onde a correlação entre fumaça e $\mathrm{SO}_{2}$ era menor $-0,52$ - do que para o conjunto de dados como um todo $-0,90$. Tanto os dados de mortalidade quanto os de poluição foram ajustados antes de cada tipo de 
análise, sendo divididos pela sua média a cada inverno, de modo a reduzir o efeito da tendência anual. $O$ estudo conclui pela existência de uma associação positiva e significativa entre a taxa bruta de mortalidade e a poluição (medida em termos de microgramas/ maje partículas em suspensão), mas não chega a resultados tão convincentes no que diz respeito à associação entre a mortalidade e a concentração de $\mathrm{SO}_{2}$. Os autores discutem a conveniência de ajuste de um modelo linear ou quadrático, optando por este último.

Uma vasta literatura vem comprovando, em diversas partes do mundo, a influência da poluição do ar na mortalidade, através de numerosos estudos. Logo após a publicação das conclusões do painel de Porto Rico, Shy (1979) polemizou com a equipe liderada por Holland, argumentando que a revisão feita por este menosprezava sistematicamente vários trabalhos que levantavam argumentos a favor do efeito deletério da poluição do ar não apenas em altas concentrações, mas mesmo com doses menores. $O$ fundo desta polêmica baseava-se em estratégias distintas adotadas pelos EUA e pela Grã-Bretanha no combate à poluição do ar. O governo inglês, desde o Clean Air Act, de 1956, implementou uma política de redução global das fumaças graças à adoção de combustíveis "limpos" na indústria e nos lares, sem se preocupar em estabelecer limites aceitáveis para cada tipo de poluente. Já nos EUA, foi só a partir do Air Quality Act, de 1967, que passou a vigorar a recomendação para que cada Estado estabelecesse um calendário definindo os niveis toleráveis dos vários poluentes. Em 1970, 。 Congresso, através do Clean Air Act, requereu ao Governo Federal o estabelecimento de padrões uniformes de qualidade do ar a nível do pais. Shy alega que, no nivel atual de conhecimentos disponiveis, apesar de não ser possível ainda identificar o efeito separado de cada poluente e seu modo específico de ação, inúmeros pesquisadores evidenciaram a existência de uma associação positiva entre efeitos adversos para a saúde e particulas em suspensão em concentrações abaixo de 240 microgramas/ $\mathrm{m}^{3}$ (medidas por $H i g h$-vol). Levanta, assim, onze trabalhos, a maioria europeus, onde foi estudado o efeito de níveis menores de poluição do ar sobre a saúde de adultos e crianças. Shy recupera também resultados obtidos pela investigaçāo conhecida por CHESS - Community Health and Environmental Surveillance Studies -, promovida pela Agência de Proteção Ambiental dos EUA e criticada devido a alguns problemas metodológicos.

As partículas em suspensão podem ser medidas por diversos métodos. Dentre os mais conhecidos está o método desenvolvido na Grã-Bretanha e adotado na Europa, conhecido como Smokeshade method ou British black Smoke, que consiste na medição da "mancha de fumaça" formada pelas partículas que passam através de um filtro, seus resultados sendo fornecidos em microgramas/metro cúbico. Outro método, adotado nos EUA e também no Brasil, é o "amostrador de grandes volumes" ( High volume method), que baseia-se na passagem do ar succionado para o interior de um abrigo, a uma vazão de 1,13 a $1,170 \mathrm{~m}^{3} /$ minuto, através de um filtro que retém as partículas menores que 100 micra. A concentração de partículas em suspensão é também expressa em microgramas por metro cúbico $H i$-vol e é calculada determinando-se a massa de material coletado e o volume de ar amostrado. Alguns estudos norteamericanos medem a concentração de partículas em unidades de "coeficientes de fumaça" (coefficient of haze-Cohs). Já se começa também no Brasil a medir as partículas menores, ditas inaláveis, através de "métodos de separação inercial" ou filtração (Holland et al., 1979; Feema, 1979; Conama, 1990).

Nos EUA, os padrões para partículas em suspensão, medidas pelo $H i$-vol, são os seguintes:

- 75 microgramas/metro cúbico, média geométrica anual para observações durante 24 horas seguidas;

- 260 microgramas/metro cúbico, nível máximo tolerável, a não ser excedido mais do que uma vez ao ano (Higgins, 1986).

No Brasil, desde 1990, passou-se a diferenciaros padrões primários de qualidade do ar, entendidos como as concentrações de poluentes que, ultrapassadas, poderão afetar a saúde da população, dos padrōes secundá- 
rios, definidos como as concentraçōes de poluentes abaixo dos yuais se prevê o mínimo efeito adverso sobre o bem estar da populaçāo, assim como o mínimo dano à fauna, flora, aos materiais e meio ambiente em geral (Conama, 1990).

Os padróes primários para as particulas totais em suspensão no Brasil são de 80 microgramas por metro cúbico de ar, concentração média geométrica anual, e concentração máxima diária de 240 microgramas por metro cúbico de ar, que não deve ser excedida mais de uma vez por ano.

Os padrões secundários são de 60 microgramas por metro cúbico e 150 microgramas por metro cúbico para, respectivamente, a concentração média geométrica anual c a concentração máxima diária (Conama, 1990).

Além de Londres, outra cidade para a qual foram feitos estudos importantes tem sido Nova York (EUA). Já desdé a década de 50, Greenburg (1962) e sua equipe analisavam as relações entre os níveis de poluição e a mortalidade. Schimmel (1976, 1978), pertencente ao mesmo grupo, prosseguiu com as investigações, abrangendo o periodo entre 1963 e 1976. No decorrer destes 14 anos, houve aproximadamente 1.250 .000 mortes na cidade. Buscou-se estabelecer as associaçōes entre as flutuaçōes da mortalidade e os niveis de dióxido de enxofre, que sofreram redução substancial ao longo do período, e de partículas em suspensão, medidas pelo método britanico da mancha (smoke shade). $\mathrm{O}$ autor eliminou, inicialmente, as tendências anuais de cada variável ao dividir os dados diários de poluição e de mortalidade por uma média móvel de 365 dias. Em seguida, suavizou os dois lados da equação (tanto a variável resposta quanto as covariáveis) através de um filtro linear, representado pelo desvio da variável de sua média móvel de 15 dias, permitindo a decomposição de cada variável em um componente lento (a média móvel) e um componente rápido (o desvio), de modo a reduzir a influência dos movimentos sazonais. Os valores extremos, que ultrapassavam a média em mais de très desvios-padrão, foram eliminados. Os dados faltantes de poluição foram interpolados a partir de outras estações, sendo que o autor utilizou os dados procedentes de uma única estação de coleta como representativos de toda a cidade. Os dados de mortalidade foram ainda corrigidos, de modo a controlar o efeito isolado da temperatura, do mesmo dia e de dias anteriores. Num estudo anterior, o mesmo autor (Schimmel \& Murawski, 1976) havia verificado a existência de forte associação entre ondas de calor, frequientes nos EUA entre maio e agosto, e flutuações da mortalidade (tanto na taxa bruta quanto na mortalidade por causas cardiovasculares e respiratórias). Não foi encontrada uma associação estatisticamente significante entre os niveis de $\mathrm{SO}_{2}$ e a mortalidade diária por todas as causas. Já entre as partículas em suspensão e a mortalidade geral (tanto a taxa bruta quanto a ajustada), foi constatada uma associação positiva e estatisticamente significante. $O$ autor fornece os resultados para os dados do mesmo dia, e para diferentes intervalos de defasagem, concluindo que as associações mais significativas limitam-se aos efeitos do mesmo dia e do dia imediatamente anterior. Desenvolve ainda uma análise classificando os dados segundo os quartis de poluição, cujos resultados o levam a sugerir um modelo com limiar (threshold), mais do que um simples modelo linear, particularmente do tipo $(\boldsymbol{P})^{\underline{\underline{x}}}$, ou seja, alguma potência das partículas em suspensão.

Outros autores também têm analisado a influência da poluição do ar na mortalidade. Assim, Jacobson (1984) estudou as informações de mortalidade, por causa e sexo, nos 31 condados mais populosos da Califómia (EUA), onde a qualidade do ar é pior nos condados mais ricos, diferentemente do habitual. Apesar das taxas de mortalidade geral estarem positivamente associadas ao grau de pobreza, à falta de instrução e ao emprego em área rural, a mortalidade por câncer revelou uma associação na direção oposta, estando positivamente correlacionada aos niveis de monóxido de carbono e de óxidos de nitrogênio.

Ainda na Califómia, Shumway et al. (1988) procuraram ajustar modelos lineares e não-lineares para explicar as possíveis associações entre a mortalidade, a poluição e variáveis climáticas em Los Angeles, no período compreendido entre 1970 e 1979. Utilizaram técnicas de análise de séries temporais para 11 séries de dados diários: 3 (três) séries de mortalidade (total, por doenças respiratórias e cardiovascula- 
res), 2 (duas) de clima (temperatura e umidade relativa), além de 6 (seis) tipos de poluentes. Após suavizar os dados originais, transformando-os em médias semanais, os autores chegaram a um modelo do tipo

$$
M_{t}=\alpha_{0}+\alpha_{1} T_{t}+\alpha_{2} T_{t}^{2}+\beta_{1} L_{n} P_{t}+X_{t}
$$

onde $M_{t}$ é a mortalidade suavizada para a semana $t$, expressa em mortes por dia. As variáveis independentes são a temperatura $T_{t} e$ a poluição $\mathrm{P}_{r}$. Os erros $\mathrm{X}_{\imath}$, aditivos e correlacionados, são supostos satisfazer um modelo auto-regressivo de ordem não especificada. Os autores concluem que as flutuaçōes da mortalidade estão fortemente associadas, em cada ano, às variaçōes $\mathrm{da}$ temperatura, combinadas aos níveis de três poluentes (monóxido de carbono, hidrocarbonetos e partículas em suspensão).

Já Buffler et al. (1988) investigaram as associações existentes entre as taxas de mortalidade por câncer de pulmão em Harris County, Texas (EUA), e a poluição do ar, concluindo que a poluição era responsável por menos de $5 \%$ da variação total intra-urbana das taxas de mortalidade por câncer pulmonar. Os autores levantam a possibilidade de que fatores de risco individuais, tais como o fumo e a ocupação, não identificados pelo estudo em questão, do tipo ecológico, tenham dificultado a obtenção de resultados mais conclusivos.

Além das pesquisas a partir de dados de mortalidade, existem atualmente inúmeros trabalhos que procuram identificar os efeitos de poluição do ar, mesmo com níveis moderados, sobre a morbidade.

Gervois et al. (1977) realizaram inquérito em duas localidades industriais do norte da França durante os meses de inverno de 1974/75, quando foram analisados todos os 3.003 pedidos de licença ou afastamento do trabalho. $O$ perfil sócio-econômico dos dois grupos investigados era semelhante. Os autores constataram a presença de associação positiva entre níveis de poluição atmosférica relativamente baixos (50 microgramas $/ m^{3}$ de "ácidos totais" e 40 microgramas $/ m^{3}$ de "fumaça negra", medida pelo método europeu) e a incidência de problemas respiratórios agudos banais (gripes, bron- quites, resfriados, etc.). Os mais afetados foram aqueles que residiam na mesma cidade onde trabalhavam.

Levy et al. (1977) desenvolveram um estudo retrospectivo relacionando os níveis de poluição do ar e as admissōes hospitalares de adultos com quadro de piora de problemas pulmonares crônicos e de crianças com IRAs, na cidade de Hamilton, Ontário (Canadá), entre julho de 1970 e junho de 1971 . Verificaram existir uma forte correlação $(r=0,77, p<0,01)$ entre o número semanal de internaçōes por causas respiratórias e o indice de poluição semanal (construído como uma ponderação do nível de partículas e de dióxido de enxofre). Ao desagregarem os dados pelos quatro hospitais distritais da cidade, constataram a existência de um gradiente, a força da associação variando inversamente com a distância entre o hospital $\mathrm{e}$ as indústrias siderúrgicas. Os níveis de $\mathrm{SO}_{2}$ também estiveram positivamente associados às flutuações das internações nas 3 (três) áreas mais poluídas da cidade. Encontrou-se uma correlação negativa moderada entre a temperatura e as admissōes, aumentando a fração da variância explicada só pelo índice de poluição de $32,4 \%$ para $37,7 \%$, após inclusão da temperatura na regressão múltipla ( $p<0,001)$. Entretanto, não se constatou associação com os níveis de oxidantes, hidrocarbonetos, óxidos de nitrogênio, pólens, umidade relativa do ar, direção ou velocidade dos ventos. Segundo dados do laboratório regional de virologia, não houve epidemia de influenza ou outros vírus no período estudado.

Mazumdar \& Sussman (1983) analisaram os efeitos dos níveis diários de poluição em Allegheny County, Pensilvânia (EUA), utilizando dados de mortalidade e de morbidade. Os autores inicialmente ajustaram os dados através de um "filtro linear", de modo a eliminar o componente sazonal através da subtração de uma média móvel de 15 dias de cada observação isolada. Em seguida, corrigiram os dados de mortalidade a fim de eliminar o efeito isolado de temperatura. Observaram, assim, uma associaçāo entre a morbidade (total e por problemas cardiovasculares) e os niveis de particulas, para o mesmo dia.

Imai et al. (1985) reviram a literatura japonesa sobre episódios de smog fotoquímico e 
sintomas, sistematizando os achados de 12 estudos realizados no Japão entre 1970 e 1976. Enquanto o padrão japonês é de $0,06 \mathrm{ppm}$ de oxidantes (média por hora), os trabalhos analisaram os efeitos de níveis tão elevados quanto $0,210 \mathrm{ppm}$ de oxidantes, relacionando três grupos de sintomas: 1) irritação ocular, lacrimejamento, dispnéia e cefaléia; 2) dor de garganta, fadiga, desconforto e percepção de odores estranhos; 3) tosse, expectoração, congestão nasal e rinorréia. Os grupos populacionais mais afetados eram, em geral, escolares e estudantes secundários, e os incidentes ocorreram muitas vezes durante a prática de educação física ao ar livre. As queixas oculares foram mais freqüentes durante o verão, quando é mais comum o smog fotoquímico. Já os sintomas respiratórios não variavam muito durante o ano, apesar de serem relatados com maior frequiencia. Os autores constataram ainda ter havido queda substancial das queixas associadas à poluição, atribuindo este declínio à substancial redução do número de dias de "alerta" por oxidantes (de $328 / 365$ dias 1973 para 86/366 dias em 1980).

Vale lembrar que os oxidantes são substancias que causam a oxidação, reação química que consiste na perda de elétrons, com aumento de valência. Os oxidantes atmosféricos sāo o ozônio, o dióxido de nitrogênio e os peróxidos orgânicos. Todos liberam iodo de soluções neutras de iodeto de potássio. $\mathrm{O}$ padrão norteamericano para o teor máximo admissivel de oxidantes fotoquímicos é de 160 microgramas por $\mathrm{m}^{3}$, equivalente a 0,08 partes por milhão (ppm), a não ser ultrapassado mais de uma vez ao ano. O mesmo padrão é adotado no Brasil (OMS, 1987; Higgins, 1986; Conama, 1990).

O ozônio $\left(\mathrm{O}_{3}\right)$ é uma variedade alotrópica do oxigênio, apresentando-se sob a forma de um gás azul pálido, de odor picante característico. Agente oxidante muito ativo e tóxico, é conside. rado como poluente em concentraçōes superiores a 120 microgramas $/ m^{3}$. Na alta atmosfera, onde se forma a partir das radiações solares ultravioletas de ondas curtas, existe em niveis bem mais elevados, uma pequena fração terminando por se misturar na baixa atmosfera. $O$ ozônio também se origina das descargas elétri. cas na atmosfera $e$ de reações fotoquímicas onde entram os hidrocarbonetos e os óxidos de nitrogênio (por exemplo, nos gases emitidos pelos canos de descarga dos automóveis com motores de combustão interna) (OMS, 1987, p. 96).

Bates \& Sizto (1987) analisaram as informações sobre poluição e admissões hospitalares na província de Ontário (sul do Canadá), no periodo entre 1974 e 1983. Esta região, habitada por cerca de 5,9 milhões de habitantes, é coberta por 17 estações que medem diariamente a poluição e dispõe de 79 hospitais para doenças agudas, cujos registros diários foram estudados. Para evitar o efeito das tendências anuais, o número de internações de cada dia foi comparado com a média de admissóes para o mesmo dia da semana, na mesma estação do ano, para cada ano. Os dados foram agrupados segundo os meses de inverno e de verão. Houve redução significativa nos níveis de dióxido de enxofre, os niveis de 1983 sendo inferiores aos de 1974 em mais de 50\%. O mesmo, entretanto, não se verificou quanto aos demais poluentes, tendo havido, inclusive, aumento dos teores de sulfatos em aerosóis $\left(\mathrm{SO}_{4}\right)$ entre 1976 e 1980 , com discreta queda em seguida. Os sulfatos $\left(\mathrm{SO}_{4}\right)$ são sais do ácido sulfúrico $\left(\mathrm{H}_{2} \mathrm{SO}_{4}\right)$ Dentre os diversos sulfatos existentes na natureza sob a forma de aerosóis, o sulfato de amônio possui propriedades ácidas em soluções aquosas, sendo altamente corrosivo. Provém, parcialmente, da reação entre os óxidos de enxofre $\mathrm{e}$ o amoníaco $\left(\mathrm{NH}_{3}\right)$, através de uma reação de oxidação (OMS, 1987). Os padrões são fornecidos apenas para o dióxido de enxofre $\left(\mathrm{SO}_{2}\right)$, que ao reagir com a água se transforma então em ácido sulfúrico. Os níveis de sulfatos foram sistematicamente mais elevados no verão do que no inverno. De forma surpreendente, a maior parte das internações por doenças respiratórias no inverno foi composta por jovens até 14 anos, e não por pessoas acima de 60 anos. Já no verão a distribuição etária dos casos fçi mais equilibrada. Através de uma análise de regressão múltipla stepwise, os autores encontraram que os teores de $\mathrm{SO}_{4}$ (defasados $24 \mathrm{hs}$ ) eram responsáveis por $3,5 \%$ da variância de todas as admissões por causas respiratórias no verão.

Para as internações por asma, a mesma variável era responsável por $2,27 \%$ da variação e, se 
incluída a temperatura da véspera, esse valor subia para $5,1 \%$, também durante o verão. Ao compararem as internações dos dias de pico de ozônio com as dos dias de mínimo, para a mesma estação e ano, por sub-região, concluíram que a elevação dos teores de ozônio pode estar associada a um aumento de 7\% das admissōes respiratórias. Já as internações por outras causas não mostraram alteraçōes devido às flutuações dos níveis de $\mathrm{SO}_{4}$ ou de $\mathrm{O}_{3}$. Os autores argumentam que as correçōes aplicadas aos dados (dividindo as internaçōes de cada dia pela média de semana e calculando-se os desvios percentuais) podem estar levando a uma subestimação dos efeitos, já que a média móvel necessariamente inclui o dia estudado. Terminam discutindo a necessidade de estudos posteriores, de modo a identificar se os aumentos na morbidade hospitalar por causas respiratórias devem-se, sobretudo, ao ozônio ou aos sulfatos, ou ainda a um outro tipo de poluente ácido, mais comum no verão, responsável pelo assim chamado "efeito da bruma ácida de verão" (acid summer haze).

Ostro \& Rothschild (1989) analisaram as informações do inquérito norte-americano HIS (Health Interview Survey), para o periodo entre 1976 e 1981. Trata-se de um inquérito nacional de morbidade que entrevista, anualmente, cerca de $\mathbf{5 0 . 0 0 0}$ familias, coletando dados sobre os problemas de saúde que aconteceram nas duas semanas anteriores, além de fornecer as características sócio-econômicas dos lares entrevistados. A amostra compõe-se de adultos entre 18 e 65 anos inseridos no mercado de trabalho. Os indicadores de morbidade utilizados foram os "dias de atividades restritas devido a causas respiratórias" (DARR) e os "dias com restrição menor de atividade" (DRMA). Os poluentes considerados foram a média das leituras diárias de partículas finas em suspensão (PF) e o ozônio $\left(\mathrm{O}_{3}\right)$, nos quinze dias anteriores. Com exceção do ozônio e da temperatura (coeficiente de correlação de 0,50 a 0,68 nos 6 anos estudados), foi baixa a correlação entre as variáveis sócio-econômicas e demográficas (sexo, idade, escolaridade, renda familiar, estado conjugal, existência de uma patologia prévia), e as duas variáveis de poluição, não ultrapassando 0,10 .
O modelo de regressão múltipla utilizado foi de forma

$$
Z=\exp (X \cdot b)
$$

onde $\mathrm{X}$ e $b$, são respectivamente, os vetores das variáveis explicativas e dos parâmetros estimados. Foi admitida uma distribuição de Poisson para a variável resposta (número de dias doentes, DARR ou DRMA).

Os autores encontraram, então, uma relação consistente entre PF e DARR em todos os 6 anos estudados, o coeficiente estimado variando entre 1,02 e 1,81 , sendo que cinco dos coeficientes estavam entre 1,45 e 1,81. Calculando o "melhor coeficiente estimado" pela ponderação de cada coeficiente de regressão, para cada ano, pelo inverso de sua variância, obtiveram o valor de 1,58 para o efeito das partículas finas sobre os DARR. Já para o ozônio, o "melhor coeficiente estimado" foi igual a zero.

Para DRMA, evidenciaram uma associação maior com os niveis de ozónio do que com as PF. Todos os resultados foram obtidos para $\mathrm{p}<0,05$, pelo menos. Os autores atribuem a não-identificação dos efeitos do ozônio aos procedimentos de medida adotadas para este poluente (média quinzenal da leitura máxima diária, por hora). Comparam ainda seus resultados àqueles obtidos por outros pesquisadores para os mesmos poluentes, concluindo pela consistência dos achados sobre a associação entre os níveis de partículas e relato de restrição das atividades por causas respiratórias.

Embora mais raros, os estudos em crianças merecem destaque, já que os efeitos de variáveis de confundimento (fumo, exposição ocupacional atual e pregressa, mobilidade durante o dia e história de migrações anteriores, etc.) podem ser melhor controlados. Assim como os idosos, considera-se em geral as crianças como grupo bastante sensível aos efeitos da poluição atmosférica.

Mais ainda, merecem ser lembradas algumas particularidades do organismo infantil. A relação entre superfície corporal e peso é 2,5 vezes maior nos neonatos do que nos adultos, 0 que leva a uma maior área de perda de calor por unidade de peso. Tal fato, associado a uma maior velocidade de crescimento, gera nas 
crianças taxas de metabolismo em repouso e de consumo de oxigênio por quilo de peso mais elevadas que as dos adultos. Em condições de repouso e equilibrio térmico, um lactente consome $7 \mathrm{ml} / \mathrm{kg}$ de oxigênio por minuto, contra 3,5 $\mathrm{ml} / \mathrm{kg}$ por minuto para um adulto nas mesmas condições. $O$ volume de ar que passa pelos pulmões de um lactente é, assim, duas vezes maior que o de um adulto em repouso, por unidade de peso corporal. Isso faz com que qualquer agente químico na atmosfera atinja duas vezes mais as vias respiratórias de uma criança entre uma semana e doze meses de idade, se comparadas às de um adulto no mesmo período de tempo. Quando a temperatura ambiente cai abaixo do nivel do equilibrio térmico, aumentam a velocidade do metabolismo $\mathrm{e}$ as necessidades de oxigênio. Como a temperatura basal das lactentes é superior à dos adultos, uma queda igual de temperatura provoca maior consumo de oxigênio nas crianças, que também necessitam de mais oxigênio devido ao choro.

Por outro lado, experimentos em ratos, mostraram que, apesar dos compostos lipossolúveis serem absorvidos a velocidades semelhantes pelos pulmões de animais jovens e adultos, os compostos químicos hidrofílicos são absorvidos mais rapidamente pelas cobaias jovens.

Devido à estatura, a exposição de crianças em idade pré-escolar aos poluentes atmosféricos pode ser mais intensa do que a de adultos quando estes poluentes são emitidos junto ao solo, como é o caso dos canos de descarga dos veículos, ou, no caso de aerosóis, quando se trata de gases ou vapores de alta densidade (OMS, 1986). Estas diferenças físiológicas aumentam, portanto, a relevância dos achados nos estudos com crianças, que poderiam ser encaradas como uma espécie de "amplificadores naturais" de fenômenos presentes na população em geral.

Um dos estudos pioneiros neste sentido foi desenvolvido por Douglas \& Waller (1966), que acompanharam uma coorte de 3866 crianças inglesas, do nascimento até o $15^{9}$ aniversário, moradoras em 2689 localidades diferentes. As áreas de residência foram agrupadas em quatro níveis distintos de poluição do ar (muito baixa, baixa, moderada e alta). Os autores constataram não haver diferença significativa na incidência de IRAs altas (coriza nasal, otites e amigdalites) por área. Já as IRAs baixas (tosse, bronquites, pneumonias lobares e broncopneumonias) foram até três vezes mais freqüentes nas crianças vivendo em áreas muito poluídas, em comparação às crianças moradoras em áreas rurais. Houve, inclusive, um efeito "dose-resposta" significativo, com gradiente crescente segundo os niveis de poluição. Lembramos que o efeito "dose-resposta" corresponde a uma relação linear entre a variável resposta e a variável explicativa. Não foram encontradas diferenças por sexo nem por nível sócio-econômico medido pela ocupação dos pais.

Numa seqüência deste mesmo estudo, Colley et al. (1973) pesquisaram a prevalência de queixas respiratórias em 3899 jovens de 20 anos pertencentes à coorte nascida em 1946. Os autores buscaram verificar a existência de associação entre a presença de tosse no inverno, o hábito de fumar, a ocupação dos pais, a exposição à poluição do ar e uma história de doenças das vias áereas inferiores antes dos 2 (dois) anos de vida. Encontraram uma frequiência maior de sintomas respiratórios (tosse crônica com ou sem expectoração) entre os fumantes do que entre os não-fumantes (teste qui-quadrado significativo, com $p<0,0005$ ). Também uma história de patologia pulmonar antes dos 2 (dois) anos de idade esteve significativamente associada $(0,025>p>0,01)$ aos problemas respiratórios. Já a exposição à poluição e a situação social da família não mostraram associação significante, vinte anos após.

Também na Grä-Bretanha, Lunn et al. (1967) avaliaram a função pulmonar de 819 crianças entre 5 e 6 anos de idade, moradoras de quatro bairros distintos da cidade de Sheffield, sujeitas a níveis distintos de poluição. As provas foram realizadas nos meses de verão, entre 1963 e 1965, de modo a minimizar os efeitos de eventuais episódios de IRAs. Os dados sobre situação social da família eram recolhidos via questionário preenchido pelos pais e através de entrevistas. Encontrou-se maior frequiência de IRAs altas, indicadas pela presença de coriza muco-purulenta e história de três ou mais resfriados por ano, assim como de episódios de IRAs baixas (tosse persistente, pneumonias e bronquites), nos bairros mais poluidos, se comparados aos bairros com ar de boa qualida- 
de. Já as características sócio-econômicas da familia mostraram-se menos associadas aos sintomas respiratórios. Encontrou-se associação apenas entre classe social dos pais, definida pela ocupação, e história de tosse persistente. As provas de função pulmonar, em contrapartida, não foram afetadas pela área ou pelos fatores sócio-econômicos, com exceção do bairro mais poluído. $O$ volume respiratório máximo de crianças com passado de infecções das vias áereas inferiores mostrou-se reduzido.

Love et al. (1981) analisaram os resultados de um estudo prospectivo envolvendo cerca de 500 familias moradoras de dois bairros de Nova York (EUA), acompanhadas por 32 semanas. Concluíram que a incidência de doenças respiratórias agudas, tanto envolvendo as vias áereas inferiores como as superiores, de pais, mães e escolares tendia a ser mais elevada nas áreas poluídas. O mesmo não se constatou para os pré-escolares.

A mesma equipe (Love et al., 1982) estudou a incidência de doenças respiratórias agudas em familias de Chattanooga, Tennessee (EUA), expostas a diferentes níveis de dióxido de nitrogênio, nos anos de 1972 e 1973. A área já havia sido investigada quatro anos antes, sendo que houve redução substancial das concentrações de poluentes no período considerado. Todas as famílias possuíam ao menos uma criança de até 12 anos de idade. Apesar de ter havido um decréscimo geral de incidência de IRAs altas, nas 3 (três) comunidades (com níveis elevados, médios e baixos de poluição), entre 1972 e 1973, não se verificou queda semelhante na freqüência de IRAs baixas, particularmente nas crianças. Persistiu, todavia, uma maior incidência de doenças respiratórias na área mais poluída vários anos após a redução do nivel médio anual de poluição, sugerindo seja a existência de efeitos retardados da exposição prévia a níveis elevados, seja a influência preponderante de exposições curtas e intermitentes a episódios agudos. A ocorrência de uma greve numa fábrica de munições altamente poluidora, em 1973, quando houve queda em quase um terço do excesso de morbidade na área mais poluída, tende a reforçar a segunda hipótese, segundo os autores.

Já Saric et al. (1981) realizaram provas de função pulmonar em escolares de duas localida- des iugoslavas com diferentes niveis de poluição do ar. Verificaram que os moradores das áreas mais poluidas apresentavam, em média, um fluxo expiratório inferior ao dos residentes na área controle, bem como exibiam taxas superiores de incidência de doenças respiratórias agudas.

Dassen et al. (1986) mediram a função pulmonar de 636 crianças holandesas entre 6 e 11 anos, durante e após um episódio agudo de intensa poluição de cinco dias de duração, e concluíram ter havido queda transitória da função pulmonar dos escolares. Esta queda ainda era percebida 16 dias após o episódio, embora 25 dias após já não fosse mais evidente.

Vedal et al. (1987) acompanharam um grupo de escolares da região de Chestnut Ridge, Pensilvânia (EUA) por 8 (oito) meses, durante os quais os pais preencheram um diário sobre sintomas de IRAs altas e baixas; o fluxo expiratório máximo de cada grupo de crianças foi medido diariamente por 9 (nove) semanas consecutivas, durante os 8 (oito) meses, com o objetivo de correlacioná-lo aos niveis diários de dióxido de enxofre, dióxido de nitrogênio, ozônio e partículas em suspensão, bem como às temperaturas minimas. Os autores encontraram associação entre a frequiência de IRAs baixas e quedas de temperatura, mas não com os teores de $\mathrm{SO}^{2}$ ou de partículas. A existência de doença no dia anterior foi o principal fator associado à presença de IRA corrente. Os autores discutem alguns problemas metodológicos envolvidos na análise, como a autocorrelação das variáveis, bem como o fato das crianças estarem sujeitas a niveis baixos de poluição, inferiores aos padrões em vigor. Levantam ainda a questão das possiveis diferenças entre exposição individual (determinada também pela poluição domiciliar) e os níveis de poluição no ambiente externo.

Avol et al. (1987) realizaram um experimento em crianças voluntárias entre 8 e 11 anos de idade que praticavam exercícios por uma hora numa área poluída de Los Angeles (EUA) e numa área com ar puro. $O$ fluxo expiratório máximo era medido antes e após os exercícios. Apesar de, enquanto grupo, não terem sido notadas diferenças nas provas pulmonares realizadas em ambientes poluídos, se comparadas às efetuadas na área controle, uma análise 
de regressão dos dados individuais mostrou haver queda significativa da função respiratória $(p<0,05)$ com o aumento dos teores de ozônio. Os autores discutem a possibilidade de que as medidas extraordinárias de controle ambiental adotadas durante os Jogos Olímpicos de 1984, associadas a uma conjunção de fatores meteorológicos favoráveis, com penetração de uma massa tropical aumentando a umidade e a turbulência, tenham contribuído para niveis de ozönio particularmente moderados, dificultando a obtenção de resultados mais conclusivos.

Já Arossa et al. (1987) evidenciaram melhoria nas provas de função pulmonar de 2042 escolares residentes em área urbana e suburbana de Turim (Itália), ao compararem os resultados de exames realizados nos invemos de 1980-1981 e aqueles obtidos em 1982-1983, quando houve queda significativa dos níveis de poluição por dióxido de enxofre e partículas ( $p<0,01$ ). Além das crianças residentes no núcleo urbano, foram examinadas, nos dois invernos, crianças moradoras de um subúrbio "limpo", que serviram de controles. A análise foi desenvolvida através de um modelo tipo GLM ("general linear model analysis") pelo SAS, incluindo-se outras covariáveis sociais e ambientais, tais como: sexo, idade, altura, peso, educação dos pais, fumo ativo e fumo passivo, número de cigarros consumidos, existência de aquecimento central e tipo de fogão utilizado. Os autores concluíram, então, que, após controle das variáveis sócio-econômicas e ambientais, as diferenças entre as crianças da área poluída $e$ da área limpa, evidentes na primeira etapa do estudo, haviam desaparecido com a queda dos níveis de poluição, sugerindo que os efeitos danosos dos poluentes para as vias áereas eram reversiveis, ao menos naquela faixa etária.

Charpin et al. (1988) estudaram a sintomatolog̣ia respiratória de crianças entre 9 e 11 anos, residentes próximas a uma mina e uma usina de carvão no sul da França e compararam a frequiência de queixas respiratórias entre moradores submetidos a diferentes concentrações de poluentes, particularmente dióxido de enxofre $\left(\mathrm{SO}_{2}\right)$. Nas áreas poluídas, verificou-se associação significativa entre os níveis de $\mathrm{SO}_{2}$ e sintomas respiratórios altos e baixos. A temperatura média diária também mostrou-se correlacionada com uma maior incidência de sintomas na maioria das áreas poluídas e também em algumas áreas não-poluídas.

Ware et al. (1984) desenvolveram um estudo longitudinal com cerca de 10.000 crianças entre 6 e 9 anos de idade moradoras de seis cidades de vários estados norte-americanos com níveis diferenciados de poluição do ar. Esta pesquisa tinha como objetivo identificar a responsabilidade de poluentes intra e extra-domiciliares na gênese de patologias respiratórias, através de questionários aos pais e provas de função ventilatória. Numa primeira etapa, os autores concluíram pela importância da exposição ao fumo passivo, sobretudo da mãe, para uma frequiência maior de problemas respiratórios. Já a exposição ao gás de cozinha mostrou uma fraca associação com queixas respiratórias ou diminuição de capacidade pulmonar.

Num desdobramento da mesma investigação, Dockery et al. (1989) analisaram a associação entre sintomas de doença respiratória crônica e a concentração de partículas e gases tóxicos $\left(\mathrm{SO}_{4}, \mathrm{SO}_{2}, \mathrm{O}_{3}\right.$ e $\left.\mathrm{NO}_{2}\right)$ das diversas cidades, após controle das covariáveis identificadas como importantes na primeira etapa do trabalho (sexo, idade, educação dos pais, fumo da mãe, utilização do gás de cozinha). Constataram existir uma correlação positiva entre os indicadores de problemas pulmonares (tosse crônica, bronquite e infecções das vias áereas inferiores) e todas as medidas de poluição particulada, incluindo-se aí a fração de sulfatos em aerosol; já a associação com os teores de $\mathrm{SO}_{2}$ e $\mathrm{NO}_{2}$, apesar de positiva, foi mais fraca.

\section{ESTUDOS NACIONAIS}

Em contraste flagrante com a profusão de trabalhos internacionais, entretanto, está nossa carência quase que absoluta de investigações brasileiras sobre o tema. Se, por um lado, já existem técnicos, ligados às agências reguladoras oficiais, tais como a Cetesb, de São Paulo, e a Feema, no Rio de Janeiro, e a algumas universidades, que têm realizado diagnósticos da qualidade do ar de nossas metrópoles, monitorando as áreas críticas e propondo até mesmo a adoção de medidas de controle em caráter de emergência, falta ainda um maior número de pesquisas que avaliem os efeitos da poluição sobre a saúde da população. 
Destaca-se, todavia, o esforço de um pequeno grupo de pioneiros nesta questão.

Sobral (1988, 1989), geógrafa brasileira que desenvolveu inquérito sobre queixas respiratórias de escolares moradores em três áreas distintas da Grande São Paulo, conseguiu levantar a existência de trabalhos de alguns estudiosos brasileiros, aos quais infelizmente não conseguimos ter acesso. Valemo-nos, portanto, de seus comentários a respeito de alguns dos trabalhos citados por ela e não localizados.

Ribeiro (1971) verificou a associação entre o número de atendimentos por infecçōes das vias áereas superiores (IVAS) e bronquite asmática em crianças menores de 12 anos, nos postos de saúde da Região de Santo André (São Paulo) e as taxas mensais de sulfatação e poeiras em suspensão, por um período de 2 (dois) anos (entre agosto 1967 e agosto 1969). Foram constatadas correlações positivas significantes entre a frequiência anual de IVAS e taxas médias anuais de sulfatos, assim como entre a incidência de bronquite e os niveis de poeiras sedimentáveis. Também se concluiu pela correlação negativa entre as IVAS e a velocidade dos ventos. Já o percentual de calmarias esteve positivamente associado aos problemas respiratórios.

Ainda segundo Sobral (1988, 1989), Alterthum et al. (1975) continuaram a investigar a saúde respiratória das crianças de Santo André, confirmando os achados do estudo anterior. Relacionaram, assim, as inversões térmicas e o aumento de material particulado no ar com uma maior incidência de crises de asma brônquica.

Em 1976, Mendes \& Wakamatsu documentaram, pela primeira vez no Brasil, os efeitos agudos de três episódios intensos de poluição do ar, ocorridos em São Caetano do Sul (São Paulo) em junho do mesmo ano. Através da revisão de 8000 atendimentos médicos feitos durante aquele mês, observou-se que os picos de morbidade coincidiram com os picos de poluição por partículas e $\mathrm{SO}_{2}$ acima dos padrões internacionais. Viu-se, ainda, que o aumento de casos de doenças respiratórias e cardiovasculares superou a elevação de atendimentos por outras causas. Também a faixa etária de pré-escolares (um a quatro anos) foi bastante afetada.
Ainda em 1976, Ribeiro et al. compararam, através de provas de função respiratória, as condições de cerca de 2000 escolares de 7 a 12 anos vivendo em duas áreas distintas da Grande São Paulo: uma região industrializada e poluída, São Caetano do Sul, e uma ainda semi-rural, Embu-Guaçu. $O$ inquérito evidenciou menores índices de capacidade ventilatória e sintomas de doenças pulmonares crônicas nas crianças da região industrial; mesmo com controle das variáveis sócio-econômicas, as diferenças permaneciam significantes.

No Rio de Janeiro, Lemle (1979) pesquisou a existência de sintomas respiratórios em dois grupos de mulheres sadias residentes na Penha, bairro poluido, e em Campo Grande, área semi-rural, encontrando diferenças que falam a favor de um efeito da poluição nas vias respiratórias, apesar do pequeno tamanho da amostra analisada (menos de 100 mulheres ao todo).

Em seu inquérito, Sobral (1988), aplicou uma versão brasileira do questionário utilizado nos EUA pelo National Heart, Lung and Blood Institute em crianças entre 12 e 13 anos de 3 (três) áreas da Grande São Paulo: Juquitiba, semi-rural, Tatuapé, no Centro de São Paulo, e Osasco, cidade industrial. A investigação foi feita nos meses de setembro, outubro e novembro, de modo a evitar os meses de inverno. Dos 34 sinais e sintomas pesquisados, a autora encontrou um gradiente nas taxas de prevalência que acompanhava aproximadamente o gradiente de poluição das 3 (três) áreas. Assim, Tatuapé, a área mais poluída, apresentou as maiores taxas de prevalência em 26 dos 34 sintomas pesquisados. Já Juquitiba evidenciou a maior taxa para apenas 3 (três) sintomas. A região de Osasco ficou com niveis intermediários. Já a análise segundo as condições sócio-econômicas das famílias mostrou uma maior proporção de familias mais pobres (aferida pelo analfabetismo dos pais e pelo número de pessoas por cômodos) em Juquitiba. Ao controlar a influência dos fatores sócio-econômicos, viu-se que mesmo assim a influência dos níveis de poluição permanecia significativa.

Loureiro (1976) realizou inquérito sobre a prevalência de doenças respiratórias em dois bairros de Salvador, Bahia, encontrando maior freqüência de queixas respiratórias na área industrial, em comparação com outra área, 
predominantemente residencial. Ainda em Salvador, Carvalho et al. (1986) investigaram a prevalência de queixas respiratórias em moradores vizinhos a uma fábrica de chocolate, tomando como referência individuos residentes num bairro não-poluído. Constataram serem as taxas de queixas pulmonares mais elevadas na área exposta do que na área controle, para todos os grupos etários.

Deve-se ressaltar também o trabalho de pesquisadores ligados à área de saúde ocupacional, tais como Naoum (1984), que estudou os efeitos hematológicos da poluição em trabalhadores de Cubatão (São Paulo), e outros.

Também nós, numa primeira tentativa de estudar o tema, investigamos, juntamente com Penna (Penna \& Duchiade, 1991) a mortalidade infantil por pneumonias segundo os diversos niveis de poluição do ar das áreas da Região Metropolitana do Rio de Janeiro, para o ano de 1980 , através de regressão linear múltipla. Verificamos que, apesar das variáveis indicadoras da renda familiar explicarem a maior parte da variação total, com apenas $5,27 \%$ de variação total podendo ser atribuída à poluição, ainda assim a poluição média anual explicava $23,7 \%$ de variação residual. Interessante notar também que ao substituirmos a variável dependente (taxa de mortalidade infantil por pneumonias) pela taxa de mortalidade infantil total e pela taxa de mortalidade infantil por diarréias, a única variável independente admitida no modelo foi a proporção de familias com renda até 2 (dois) salários mínimos mensais. Um estudo mais aprofundado, analisando as associações entre a mortalidade infantil na Região Metropolitana do Rio de Janeiro e a poluição do ar, no período 1976-1986, encontra-se publicado em outra parte (Duchiade, 1991).

\section{ALGUMAS QUESTÕES POLÊMICAS}

Existem, todavia, inúmeras dificuldades na avaliação dos efeitos da poluição sobre a saúde, a começar pela própria definição dos assim chamados "efeitos". Ferris (1978) sitematizou aspectos relevantes desta discussão. Assim, se não resta dúvida que os excessos de mortalidade são eventos indesejáveis, a mesma certeza não se aplica à avaliação de outros fenômenos.
Com o aprimoramento dos instrumentos de medida, passou a ser possivel identificar reações, a nível bioquímico e até mesmo molecular, que fazem parte dos processos adaptativos necessários à própria sobrevivência.

A incapacidade de reagir a fatores externos de estresse, ou a falencia em manter uma constância razóavel do meio interno, pode ter um efeito deletério sobre a saúde. A poluiçāo do ar pode ser então considerada como exemplo de estresse externo e, quando severa, pode provocar aumento da mortalidade em grupos suscetiveis... (Ferris, 1978: 482).

Já o significado dos efeitos de teores mais moderados de poluentes apresenta maiores dificuldades.

Também o conceito de limiar não pode ser utilizado isoladamente, necessitando, em geral, ser relacionado a um efeito específico. Haveria, por assim dizer, "famílias ou séries de limiares", uma para cada efeito; quando reunidas, teríamos uma relação integrada tipo "dose-resposta", num contínuo de efeitos, dos relativamente menores aos mais severos. Ainda na opinião de Ferris, seria interessante estabelecer tais relaçōes "dose-resposta", de modo a auxiliar as autoridades na tomada de decisōes quanto ao grau de risco que a sociedade está disposta a tolerar. "Se a decisão for a de proteger a todos, mesmo o mais sensivel, então os niveis de poluição deverão ser próximos aos encontrados na natureza" (Ferris, 1978).

Antes de prosseguir, portanto, é preciso discutir, embora de forma breve, alguns pontos polêmicos que têm sido arguiidos contra os assim chamados estudos ecológicos, que abordam as relações entre poluição do ar e morbi-mortalidade.

Numa extensa revisão (mais de 90 trabalhos comentados) sobre os efeitos dos óxidos de enxofre e das partículas em suspensão sobre a saúde humana, Ware et al. (1981) sistematizaram as principais críticas aos estudos observacionais ao analisarem os achados, até aquela data ,de trabalhos que satisfizessem os seguintes critérios:

a) Tivessem sido publicados;

b) Medissem tanto o dióxido de enxofre quanto as particulas em suspensão; 
c) Controlassem os principais fatores de confusão, particularmente a temperatura, nos estudos de episódios agudos, e o fumo, a raça $e$ as condiçōes sócio-econômicas nos estudos de exposição crônica;

d) As concentraçōes de ambos os poluentes fossem inferiores a 1000 microgramas $/ \mathrm{m}^{3}$;

e) A coleta de dados, a análise e interpretação dos resultados estivessem livres de viés potencial ou erros que pudessem afetar substancialmente os resultados (Ware et al., 1981: 257).

Assim, comentam injcialmente os trabalhos clássicos de Martin \& Bradley sobre os incidentes ocorridos em Londres entre 1958 e 1960. Argumentam que os autores nāo foram capazes de isolar os efeitos separados do $\mathrm{SO}_{2}$, das partículas e do fog em si; esta crítica, a nosso ver, não diminui a relevância desses estudos, já que ofog e as partículas representam, por sua própria definição, um complexo de poluentes, sendo, portanto, "medidas brutas" da poluição atmosférica.

Os autores discutem a seguir os resultados obtidos em Nova York (EUA) por Greenburg (1962), Schimmel $(1976,1978)$ e Buechley (1973), entre outros, concluindo que os efeitos da temperatura e de outras variáveis meteorológicas - fatores estes que atuam como variáveis de confundimento - dificultam a apuração das consequiências da poluição ambiental a partir de pequenas flutuações da mortalidade, com base em estudos ecológicos.

Os autores comparam ainda os resultados de diversos estudos que focalizam as repercussões de episódios agudos de poluição sobre a morbidade, tanto sobre a piora de doentes crônicos (cardíacos, asmáticos ou portadores de bronquite) quanto sobre a incidência de doenças respiratórias agudas, além de estudos sobre a função pulmonar. Consideram como pouco conclusivos os estudos revistos.

Finalmente, revêm trabalhos que mediram os efeitos sobre a mortalidade da exposição crônica aos poluentes, via análise de regressão múltipla, a lém de estudos transversais de morbidade. Suas críticas principais fundamentam-se nos seguintes pontos: existência de colinearidade (elevada correlação) entre os poluentes e as demais variáveis explicativas; dificuldade em especificar os tipos de poluentes responsáveis pelos efeitos; dificuldade em determinar o grau de exposição dos diferentes grupos populacionais; existência de fatores de confundimento individuais, tais como fumo, poluição domiciliar, tipo de ocupação, mobilidade intra-urbana, etc; no caso dos inquéritos, impossibilidade de obter-se associações causais, na medida em que o efeito é medido simultaneamente à suposta causa (poluição); ausência de concordância entre os diversos estudiosos sobre a existência de uma relação linear (dose-resposta) ou de uma relação com limiar entre a poluição e a mortalidade.

Parece-nos, todavia, que embora cada um desses argumentos deva ser considerado e mereça discussão, nem por isso estariam invalidadas as conclusões da maioria dos 91 estudos comentados. Se "a epidemiologia é a arte de tirar conclusões razóaveis a partir de dados imperfeitos" (American Journal of Epidemiology, 1979), os riscos de viés nos estudos ecológicos são reconhecidos por todos os epidemiologistas. Entretanto, o caminho até hoje tem sido este: observações feitas por clínicos suscitam estudos ecológicos, em seguida inquéritos, estudos tipo caso-controle ou longitudinais. Os estudos experimentais visando descobrir os mecanismos fisiopatológicos pelos quais atuam determinados agentes tóxicos correm paralelamente e sofrem de severas limitações por não poderem, em geral, ser aplicados em seres humanos. Foi assim no caso do fumo, da leucemia provocada por radiações ionizantes, etc. Que os estudos ecológicos não permitem que se estabeleçam relações causais é sabido; porém, que, mesmo assim, são importantes e necessários numa primeira abordagem é a nossa opinião.... No fundo, o que está por trás de toda esta polêmica é o estabelecimento de critérios para os niveis máximos toleráveis de poluição, que envolvem gastos elevados para a adoção de medidas de controle. Nas palavras dos próprios autores, a medida direta e o controle cuidadoso de fatores de confundimento potenciais, bem como uma medida mais apurada da exposição individual à poluiçāo, serāo especialmente importantes. A necessidade de tais pesquisas deverá crescer com a alteração dos padrōes de consumo de energia, em resposta à limitada disponibilidade de petróleo e gás natural (Ware 
et al., 1981: 274). Interesses econômicos poderosos permeiam, embora não explicitamente, esta discussão.

O mesmo grupo de autores manteve, sete anos depois, sua postura crítica diante dos estudos observacionais. Segundo Ferris et al. (1988), estamos nos aproximando do fim de uma era na epidemiologia da poluição do ar. A abordagem tradicional para a medida de exposição parece ineficaz para o desafio de avaliar os riscos para a saúde, numa época de ampla exposiçāo a níveis moderados de poluição. Como as medidas de exposição individual $e$ micro-ambiental são caras, estudos dirigidos para medidas de exposição total serão menores e mais intensivos. Como permitem a análise de individuos, e não de grupos, entretanto, não necessitam ser menos poderosos (Ferris et al., 1988: 126-7).

Estudos que avaliam as diferenças de exposição intra e extradomiciliar já começam a ser realizados fora do Brasil. Assim, Stock et al. (1985) compararam, durante 6 (seis) meses (de maio a outubro), os resultados de medições de diversos poluentes (ozônio, dióxidos de nitrogênio e de enxofre, partículas de diversos diâmetros, pólens, esporos, além de temperatura e de umidade relativa do ar) colhidas através de 3 (três) tipos diferentes de instrumentos: estação fixa, estação móvel e exposição individual, na região de Houston, Texas (EUA). Evidenciaram variações ponderáveis nas concentrações de diversos poluentes, durante o dia e à noite, intra e extra-residência, e inter-domicílios.

Na Arábia Saudita, Rowe et al. (1985) compararam as partículas em suspensão intra $e$ extradomiciliares em Riad. A média de partículas em suspensão totais nos ambientes externos foi de $662 \mathrm{microgramas} / \mathrm{m}^{3}$, enquanto dentro das casas foi de 167 microgramas $/ \mathrm{m}^{3}$. Para partículas inaláveis com diâmetro menor que 10 micra, a média ao ar livre foi de 137 microgramas $/ \mathrm{m}^{3}$, enquanto a média no interior das residências foi de $78 \mathrm{microgramas} / \mathrm{m}^{2}$.

A importância dos ditos "fatores de confundimento" foi aferida, por exemplo, num estudo longitudinal com cerca de 3200 escolares de Hamilton (Canadá), entre 1978 e 1979 (Pengelly et al., 1984). Os autores investigaram a distribuição das covariáveis sócio-económicas (ocupação dos pais, renda familiar, densidade de moradores por domicilio, status migratório) e ambientais (fumo dos pais, uso de gás de cozinha), além de sintomas de problemas respiratórios (da criança e de família), segundo as áreas da cidade, classificadas em 4 (quatro) quadrantes por graus diferentes de poluição do ar. Evidenciaram, assim, que as crianças do núcleo industrial apresentavam maior prevalência de uso de gás de fogão, fumo no lar, tosse dos pais, doenças respiratórias entre irmãos, hospitalização por causas respiratórias na infância, maior aglomeração no domicílio, baixa renda familiar e emprego em ocupações não especializadas, bem como maiores niveis de poluição do ar extradomiciliar. Já as áreas com melhor qualidade do ar tinham, em geral, menor prevalência dos mesmos fatores.

Na mesma linha de preocupações, Lippmann \& Lioy (1985) discutem aspectos críticos envolvidos na maioria dos estudos sobre saúde e poluição, tais como: a exposição aos poluentes extra e intradomiciliares; a influência do tipo de atividade física na absorção de poluentes; a sensibilidade individual; a contribuição separada de exposições a picos recentes ou de longo prazo. No caso da poluição por partículas, os autores alertam sobre a necessidade de considerar o efeito da composição e do diâmetro das mesmas. Propõem, assim, o estabelecimento de índices mais acurados para estimar a exposição a partículas, bem como a aferição dos efeitos de modo mais preciso; sugerem também o aproveitamento de fontes de dados mais uniformes e abrangentes, tais como os registros ambulatoriais, além da identificação de populações expostas e de subgrupos suscetíveis.

Num recente painel internacional realizado em Pittsburgh (EUA) com diversos especialistas de renome (Schneiderman, 1988; Smith, 1988; Lippmann \& Thurston, 1988; Gardner, 1988; Greenhouse, 1988; Health, 1988), discutiu-se problemas relativos aos estudos observacionais no campo da "epidemiologia ambiental". As questões envolvidas nas medidas de exposição, na realização de comparaçōes adequadas e no manejo dos fatores de confundimento (o mesmo "efeito" derivando de diferentes "causas") foram exaustivamente debatidas.

Uma das alternativas levantadas, além da necessidade de estreita colaboração entre os epidemiologistas e os estatísticos, foi a adoção 
dos métodos da assim chamada "meta-análise". Esta vertente, bastante recente na área da Sáude Pública, teve sua origem na comparação entre diversos ensaios clínicos e terapêuticos que, por envolverem experimentos em seres humanos, são, por definição, de difícil realização, tendo de lidar com amostras pequenas. Entretanto, a arte de combinar resultados de investigações de procedências distintas e metodologias variadas tem mostrando resultados promissores, na medida em que os achados apresentam coerência e consistência (internas e externas).

Como se sabe, os estudos epidemiológicos nos fornecem somente indicaçōes sobre a existência de associações entre os poluentes e a saúde humana. A partir destas "pistas", os pesquisadores passam a planejar investigações capazes de fornecer resultados mais conclusivos. Em última instância, apenas os experimentos, sob condições de laboratório controladas, podem comprovar ou não as hipóteses levantadas nos trabalhos observacionais.

A necessidade de prosseguir e aprofundar o estudo dos efeitos da poluição do ar sobre a saúde humana, tanto do ponto de vista epidemiológico quanto do ponto de vista biológico e até mesmo físico-químico, parece ter ficado bastante evidente. Esperamos ter de alguma forma contribuído nesta direção.

\section{RESUMO}

\section{DUCHIADE, M. P. Poluição do Ar e}

Doenças Respiratórias: Uma Revisão. Cad. Saúde Públ., Rio de Janeiro, 8 (3): 311-330, jul/set, 1992.

Embora saiba-se de longa data que o fumo é o principal poluente de ar lesivo às vias respiratórias, ainda não se estabeleceu o mesmo consenso a respeito dos efeitos dos demais poluentes atmosféricos sobre a saúde. Nesta revisão, buscou-se organizar as referências recentes a respeito de ação de diversos agentes poluidores sobre a saúde respiratória, tais como as partículas em suspensão, os óxidos de nitrogênio, os sulfatos e o ozônio, entre outros. A maioria dos estudos baseou-se em dados de mortalidade, sobretudo de adultos, apesar de já existirem trabalhos que investigam também os efeitos na morbidade, tanto de adultos quanto de crianças. Os primeiros estudos foram feitos em Londres e, posteriormente, em Nova York, mas atualmente inúmeros outros grupos canadenses, norte-americanos e europeus têm se debruçado sobre a questão. Tentou-se ainda rever os vários estudos nacionais a respeito do tema, de modo a fornecer um panorama geral dos conhecimentos disponíveis até o momento.

Palavras-Chave: Poluição do Ar; Doenças Respiratórias; Saúde Ambiental; Toxicologia Ambiental

\section{REFERÊNCIAS BIBLIOGRÁFICAS}

AMERICAN JOURNAL OF EPIDEMIOLOGY, 1979. Vol. 110, n² 5, p. 525, (Nota do Editor).

ANDERSON, D. O., 1967. The effects of air contamination on Health. Part I. Canadian Medical Association Journal, 97: 528-536.

AROSSA, W.; SPINACI, S.; BUGIANI, M., NATALE, P.; BUCCA, C. \& CANDUSSIO, G., 1987. Change in lung function of children after an air pollution decrease. Archives of Environmental Health, 42: 170-174.

AVOL, E. L.; LINN, W. S.; SHAMOO, D. A.; SPIER, C. E.; VALENCIA, L. M.; VENET, T.G.; TRIM, S. C. \& HACKNEY, J. D., 1987. Short-term respiratory effects of photochemical oxidant exposure in exercising children. Journal of the Air Pollution Control Association, 37: 158-162.

BATES, D. V. \& SIZTO, R., 1987. Air Pollution and Hospital Admissions in Southern Ontario: The Acid Summer Haze Effect. Environmental Research, 43: 317-331.

BONHAM, G. S. \& WILSON, R. W., 1981. Children's health in families with cigarette smokers. American Journal of Public Health, 71: 290-293.

BUECHLEY, R. W.; RIGGAN, W. B.; HASBELBLAD, V. \& VANBBRUGGEN, J. B., 1973. $\mathrm{SO}_{2}$ levels and perturbations in mortality. Archives of Environmental Health, 27: 134-137.

BUFFLER, P. A.; COOPER, S. P.; STINNETT, S.; CONTANT, C.; SHIRTS, S.; HARDY, R. J.; AGU, V.; GEHAN, B. \& BURAU, K., 1988. Air pollution and lung cancer mortality in Harris County, Texas, 1979-1981. American Journal of Epidemiology, 128: 683-699. 
CARVALHO, F. M.; SILVANY NETO, A. M. \& LIMA, M. E. C., 1986. Doenças do aparelho respiratório numa população residente nas proximidades de uma fábrica de chocolate em Salvador, Bahia. Revista Baiana de Saúde Pública, 13: 33-46.

CHARPIN, D; KLEISBAUER, J. P.; FONDARAI, J.; GRALAND, B.; VIALA, A. \& GOUEZO, F., 1988. Respiratory symptoms and air pollution changes in children: the Gardanne Coal-Basin study. Archives Environmental Health, 43: 22-27.

COLLEY, J. R. T.; DOUGLAS, J. W. B. \& REID, D. D., 1973. Respiratory disease in young adults: influence of early childhood respiratory tract illness, social class, air pollution and smoking. British Medical Journal, 3: 195-198.

CONSELHO NACIONAL DO MEIO AMBIENTE, 1990. Resolução CONAMA 003/90. Brasilia: Conama. (Mimeo)

DASSEN, W.; BRUNEKREEF, B.; HOEK, G.; HOESCHREUDER, P., STAKTSEN, B.; GROOT, H.; SCHOUTEN, E. \& BIERSTEKER, K., 1986. Decline in children's pulmonary function during an air pollution episode. Journal of the Air Pollution Control Association, 36: 12231227.

DOLL, R. \& HILL, A. B., 1954. The Mortality of Doctors in Relation to their Smoking Habits. British Medical Journal, pp. 1451-1455.

DOUGLAS, J. W. B. \& WALLER, K. E., 1966. Air pollution and respiratory infection in children. British Journal of Preventive and Social Medicine, 20: 1-8.

DUCHIADE, M. P.; CARVALHO, M. L. \& LEAL, M. C., 1989. As mortes "em domicílio" de menores de um ano na Região Metropolitana do Rio de Janeiro - "evento-sentinela" na avaliação dos serviços de saúde. Cadernos de Saúde Pública, 5: 251-263.

DUCHIADE, M. P., 1991. Mortalidade Infantil por Pneumonias na Região Metropolitana do Rio de Janeiro, 1976-1986. Tese de Mestrado, Rio de Janeiro: Escola Nacional de Saúde Pública, Fundação Oswaldo Cruz.

FERGUSSON, D. M.; HORWOOD, L. J.; SHANNON, F. T. \& TAYLOR, B., 1981. Parenteral smoking and lower respiratory illness in the first 3 years of life. Journal Epidemiology and Community Health, 35: 150-154.

FERRIS, B. G. JR., 1978 . Health Effects exposure to low levels of regulated air pollutant: a critical review. Journal of the Air Pollution Control Association, 28: 842-897.
FERRIS, B. G. JR.; WARE, J. H. \& SPENGLER, J. D., 1988. Exposure Measurement for Air Pollution Epidemiology. In: Epidemiology and Health Risk Assessment (L. Gordis, ed.), pp. 120-128, New York: Oxford University Press.

FIELDING, J. E., 1986. Smoking: health effects and control. In: Maxcy-Rosenau Public Health and Preventive Medicine (J. M. Last, ed.), $12^{\circ}$ ed., pp. 999-1038, Norwalk: Appleton-Century-Crofts.

GARDNER, M. J., 1988. Epidemiological studies of environmental exposure and specific diseases. Archives of Environmental Health, 43: 102108.

GERVOIS, M.; DUBOIS, G.; GERVOIS, S.; QUÉTÚ, J-M.; MULLER A. \& VOISIN, C., 1977. Pollution atmosphérique deniveau modéré et affections respiratoires d'origine banale. Enquête de Demain - Quiévrechain (Nord.). Revue d'Epidemiologie et de Santé Publique, 25: 195-207.

GREENBERG, R. A.; HALEY, N. J.; ETZEL, R. A. \& LODA, F. A., 1984. Measuring the exposure of infants to tobacco smoke: Nicotine and cotinine in urine and salive. New England Jouranl of Medicine, 310: 1075-1078.

GREENBURG, L.; JACOBS, M. B. \& DROLETTI, B. N., 1962. Report of an air pollution incident in New York City, november 1953. Public Health Reports, 77: 7-16.

GREENHOUSE, J. B., 1988. Commentary on "epidemiological studies of environmental exposure and specific diseases". Archives of Environmental Health, 43: 109-111.

HEALTH, C. W., 1988. Uses of epidemiologic information in pollution episode management. Archives of Environmental Health, 43: 75-82.

HIGGINS, I., 1986. Air pollution. In: Maxcy-Rosenau Public Health and Preventive Medicine (J. M. Last, ed.), $12^{\circ}$ ed., pp. 576-586, Norwalk: Appleton-Century-Crofts.

HOLLAND, W. W.; BENNETT, A. E.; CAMERON, I. R.; FLOREY, C. V.; LEEDER, S. P.; SCHILLING, R. S. F.; SWAN, A. V. \& WALLER, R. R., 1979. Health effects of particulate pollution: reappraising the evidence: special issue on particulate air pollution. American Journal of Epidemiology, 110: 525-679.

IMAI, M.; KATSUMI, Y.; KOTCHMAR, D. J. \& LEE, K., 1985. A Survey of Health Effects Studies of Photochemical Air Pollution in Japan. Journal of the Air Pollution Control Association, 35: 103-108. 
JACOBSON, B. S., 1984. The role of air pollution and other factors in local variations in general mortality and cancer mortality. Archives of Environmental Health, 3: 306-313.

LAST, J. M., 1986. Housing and Health. In: MaxcyRosenau Public Health and Preventive Medicine (J. M. Last, ed.), 12! ed., pp. 891-898, Norwalk: Appleton-Century-Crofts.

LEMLE, A., 1979. Sintomas respiratórios e testes espirográficos: população sadia e não-fumante de duas áreas com graus diferentes de poluição atmosférica no Rio de Janeiro. Revista de Divisão Nacional de Pneumologia Sanitária, 23: 11-16.

LEVY, D; GENT, M \& NEWHOUSE, M. T., 1977. Relationship between acute respiratory illness air pollution levels in a industrial city. American Review of Respiratory Diseases, 116: 167-173.

LIPPMANN, M. \& THURSTON, G. D., 1988. Exposure assessment: input into risk assessment. Archives of Environmental Health, 43: 113-123.

LIPPMANN, M. \& LIOY, P. J., 1985. Critical issues in air pollution epidemiology. Environmental Health Perspectives, 62: 243-258.

LOUREIRO, S.; PITTA, A. M.; ALMEIDA, M. R. \& BIÃO, D. R. C., 1976. Poluição do Ar e Afecçōes do Aparelho Respiratório. Revista Baiana de Saúde Pública, 3: 25-28.

LOVE, G. J.; LAN, S-P.; SHY, C. M. \& STRUBA, R. J., 1981. The incidence and severily of acute respiratory illness in families exposed to different levels of air pollution, New York Metropoli$\tan$ Area, 1971-1972. Archives of Environmental Health, 36: 66-73.

LOVE, G. J.; LAN, S-P.; SHY, C. M.; RIGGAN, W. B., 1982. Acute respiratory illness in families exposed to nitrogen dioxide ambient air pollution in Chattanooga, Tennessee. Archives of Environmental Health, 37: 75-80.

LUNN, J. E.; KNOWELDEN, J. \& HANDYSIDE, A. J., 1967. Patterns of respiratory illness in Sheffield infant school children. British Journal of Preventive and Social Medicine, 21: 7-16.

MARTIN, A. E. \& BRADLEY, W. H., 1960. Mortality, fog and atmospheric pollution: an investigation during the winter of 1958-1959. Monthly Bulletin of the Ministery Health - Public Health Laboratory Services, 19: 56-72.

MAZUMDAR, S.; SCHIMMEL, H. \& HIGGINS, I. T. T., 1982. Relation of daily mortality to air pollution: an analysis of 14 London winters, 1958/59-1971/72. Archives of Environmental Health, 37: 213-220.
MAZUMDAR, S. \& SUSSMAN, N., 1983. Relationships of air pollution to health: Results from the Pittsburgh Study. Archives of Environmental Health, 38: 17-24.

MENDES, R. \& WAKANATSU, C. T., 1976. Avaliação de efeitos agudos sobre a saúde, através do estudo da morbidade diária em São Paulo. São Paulo: Cetesb. (Mimeo.)

MINISTÉRIO DA SAÚDE, 1984 b. Assistência $e$ Controle das Infecções Respiratórias Agudas. Brasilia: Ministério da Saúde.

NAOUM, P. C.; MOURAO, C. A. \& RUIZ, M. A., 1984. Alterações hematológicas induzidas por poluição industrial em moradores e industriários de Cubatão, SP (Brasil). Revista de Saúde Pública, 18: 271-277.

OMS, 1979. Controlling the smoking epidemic. Geneva: WHO. (Technical Report Series, 636). , 1985. Infecciones de las vias respiratórias. In: Manual de Resoluciones y Decisiones de la Asemblea Mundial de la Salud y del Consejo Ejecutivo (1973-1984), vol. 2, p. 154, Genebra: OMS.

, 1986. Principles for evaluating health risks from chemicals during infancy and early childhood: the need for a special approach. Environmental Health Criteria, 59. Geneva: WHO. , 1987. Glossaire de la pollution de l'air. Copenhague: OMS.

OSTRO, B. D. \& ROTHSCHILD, S., 1989. Air pollution and acute respiratory morbidity: an observational study of multiple pollutants. Environmental Research, 50: 238-247.

PANDEY, M. R.; SMITH, K. R.; BOLEIJ, J. S. M. \& WAFULA, E. M., 1989. Indoor air pollution in developing countries and acute respiratory infection in children. The Lancet, 25: 427-428.

PENGELLY, L. D.; KERIGAN, A. T.; GOLDSMITH, C. H. \& INMAN, E. M., 1984. The Hamilton study: distribution of factors confounding the relationship between air quality and respiratory health. Journal of the Air Pollution Control Association, 34: 1039-1043.

PENNA, M. L. F. \& DUCHIADE, M. P., 1990. Poluição do ar e mortalidade infantil por pneumonia na Região Metropolitana do Rio de Janeiro. Boletin de la Organización Panamericana de la Salud, 110: 199-207.

RIBEIRO, H. P., 1971. Estudo das correlações entre infecções das vias aéreas superiores, bronquite asmatiforme e poluição do ar em menores de 12 anos em Santo André. Pediatria Prárica, 42: 9. (org.), 1976. Estudo da função ventilatória em escolares vivendo em área com diferentes niveis de poluição do ar. São Paulo. 
ROMIEU, I., 1990. Comunicação pessoal.

ROWE, D. R.; NOUH, M. A; AL - DHOWALIA, K. H. \& MANSOUR, M. E., 1985. Indoor - outdoor relationship of suspended particulate-matter in Riyadh, Saudi Arabia. Journal of the Air Pollution Control Association, 35: 24-28.

SALES, J. A., 1978. Meteorologia e poluição do ar. Rio de Janeiro: Feema.

SARIC, M.; FUGAS, M. \& HRUSTIC, O., 1981. Effects of urban air pollution on school-age children. Archives of Environmental Health, 36: 101-108.

SCHNEIDERMAN, M., 1988. Methods: Statistics and epidemiology - Tecnology and Science. Archives of Environmental Health, 43: 133-137.

SCHIMMEL, H. \& MURAWSKI, T. J., 1976. The relation of air pollution to mortality. Journal of Occupation Medicine, 18: 316-333.

SCHIMMEL, H., 1978. Evidence for possible acute health effects of ambient air pollution from time series analysis: methodological questions and some new results based on New York City daily mortality, 1963-1976. Bulletin of the New York Academy of Medicine, 54: 1052-1108.

SHY, C., 1979. Epidemiologic evidence and the United States air quality standards. American Journal of Epidemiology, 110: 661-170.

SHUMWAY, R. H.; AZARI, A. S. \& PAWTTAN, Y., 1988. Modelling mortality fluctuations in Los Angeles as functions of pollution and weather effets. Environmental Research, 45: 224-241.

SMITH, A. H., 1988. Epidemiologic input to environmental risk assessment. Archives of Environmental Health, 43: 124-129.
SOBRAL, H. R,, 1988. Poluição do ar e doenças respiratórias em crianças da Grande São Paulo: um estudo de geografia médica. Tese de Doutorado, São Paulo: Departamento de Geografia, Faculdade de Filosofia, Letras e Ciências Humanas, Universidade São Paulo. , 1989. Air pollution and respiratory diseases in children in São Paulo, Brazil. Social Science and Medicine, 29: 959-964.

STOCK, T. H.; KOTCHMAR, D. J.; CONTANT, C. F.; BUFFLER, P. A.; HOLGUIN, A. H.; GEHAN, B. M. \& NOEL, L. M., 1985. The estimation of personal exposures to air pollutants for a community - based study of health effects insthmatics - design and results of air monitoring. Journal of the Air Pollution Control Association, 35: 1266-1273.

VEDAL, S.; SCHENKER, M. B.; MUÑOZ, A.; SAMET, J.; BATTERMAN, S. \& SPEIZER, F. E., 1987. Daily air pollution effects on children's respiratory symptons and peak expiratory flow. American Journal of Public Health, 77: 694-698.

WARE, J. H.: THIBODEAU, L. A.; SPEIZER, F. E.; COLOME, S. \& FERRIS JR., B. G., 1981. Assessment of the health effects of atmospheric sulfur oxides and particulate matter: evidence from observational studies. Environmental Health Perspectives, 41: 255-276.

WARE, J. H.; DOCKERY, D. W.; SPIRO, A; SPEIZER, F. E. \& FERRIS JR., B. G., 1984. Passive smoking, gas cooking and respiratory health of children living in six cities. American Review of Respiratory Diseases, 129: 366-374. 